\title{
Numerical Simulation of centrifugal compressor impeller flow flied based on ANSYS Workbench
}

\author{
SUN Jiao ${ }^{1,2}$, DING Jin ${ }^{2,3}$, CHEN Songying ${ }^{1}$, LI Jianfeng ${ }^{1}$ \\ (1 School of Mechanical Engineering, Shandong University, Jinan 250061, China \\ 2 School of Mechanical, Electrical and Information Engineering, Shandong University, Weihai \\ 264209, China \\ 3. Weihai Vocational College, Weihai 264209, China)
}

\begin{abstract}
Keywords: centrifugal compressor; numerical simulation; fluid-structure interaction; components transport

Abstract. Based on the finite element analysis software ANSYS Workbench, studied the fluid-solid coupling numerical simulation of the pipeline centrifugal compressor impeller with the unstructured grid finite volume method and finite element method. The equivalent stress distribution of the impeller, which caused by the centrifugal load, the coupling effect of centrifugal load and aerodynamic load, is analyzed. Based on the fluid components transport theory, the distribution of $\mathrm{H}_{2} \mathrm{~S}$ in the flow field inside the impeller is analyzed, and discussed the influence law of pitting corrosion pits on the stress distribution and the $\mathrm{H}_{2} \mathrm{~S}$ concentration of the centrifugal compressor impeller blade.
\end{abstract}

\section{Introduction}

Pipeline centrifugal compressor is the core mechanical equipment of the modern industry, is widely used in the major national project which is " West-to-East Gas Transmission". Therefore, while its impeller operates at a high speed in poor working conditions, it is subjected to rotary centrifugal force and vibration force, which may cause SCC and corrosion fatigue fractures. Once these fractures occur, the mechanical properties of the centrifugal compressor drop notably and serious accidents may take place[1]. Therefore, it has important implications for the study of stress corrosion behavior and mechanism of the impeller to understand the essence of the internal flow field of impeller by analyzing the stress and corrosion medium concentration distribution in the impeller blade.

Sulfide stress corrosion cracking (SSCC) usually occurs in the centrifugal compressor used in the petrochemical industry[2]. This kind of rupture can lead to unexpected, sudden failure as SSCC can make the metal material break down early even if the stress is below the yield strength. Local and foreign scholars have conducted many studies on SSCC and found that the concentration of $\mathrm{H}_{2} \mathrm{~S}$ has noticeable influence on the stress corrosion, the extent of damage increased with the increase of $\mathrm{H}_{2} \mathrm{~S}$ concentration in a certain range[3].

With the development of computer technology, the numerical simulation method has been used more often for studying the compressor internal flow field. In this paper, the pressure distribution and the stress and deformation conditions of the centrifugal compressor impeller were studied based on the uniflow fluid-solid coupling numerical simulation with the CFX and Static Structural module of the finite element analysis(FEA) software ANSYS Workbench, and the distribution of $\mathrm{H}_{2} \mathrm{~S}$ in the flow field inside the impeller is analyzed with the components transport theory.

\section{Analysis of impeller fluid field}

\section{Numerical methods}

The studied pipeline centrifugal compressor impeller has 15 blades, the inlet pressure is $0.17 \mathrm{MPa}$, the temperature is $77^{\circ} \mathrm{C}$, the rotating speed is $4800 \mathrm{rpm}$ and the transport medium are $\mathrm{H}_{2} \mathrm{~S}$ and $\mathrm{CH}_{4}$ which molar percentage concentration are $30 \%$ and $70 \%$. 
In this paper, the flow channel model are established with the Pro Engineer software, as shown in Fig.1.

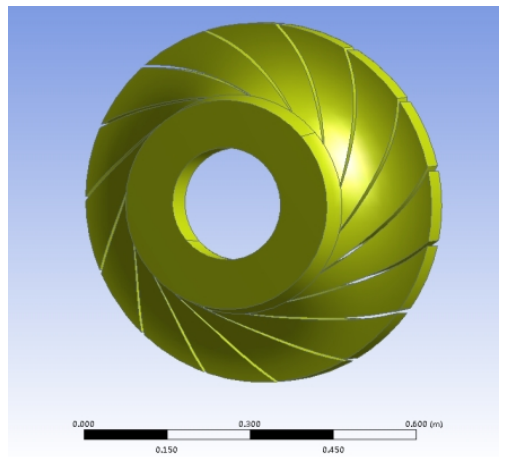

Fig.1 Flow field model of impeller

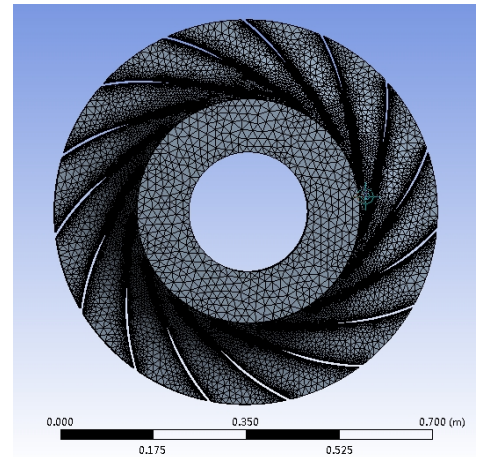

Fig. 2 FEA model of flow field

The finite element mesh of fluid field model, shown in Fig.2, was built using the unstr uctured hybrid mesh method and consists of 2276156 elements and 478092 nodes.

In this paper the three dimensional steady numerical calculation of the centrifugal compressor impeller internal flow field was performed by using the Navier-stokes equation and RNG $k$ - epsilon model with the computational fluid dynamics software CFX, and the fluid flow characteristics of each composition was analyzed with the fluid transport equation.

\section{Results and analysis}

The total pressure of internal flow field in the centrifugal compressor impeller is shown in Fig.3. The pressure of blade pressure side is significantly higher than that of the suction side. Due to the work of the impeller, the impeller flow pressure increases from the impeller import to the export, and the maximum value is at the exit, which is $0.17 \mathrm{MPa}$.

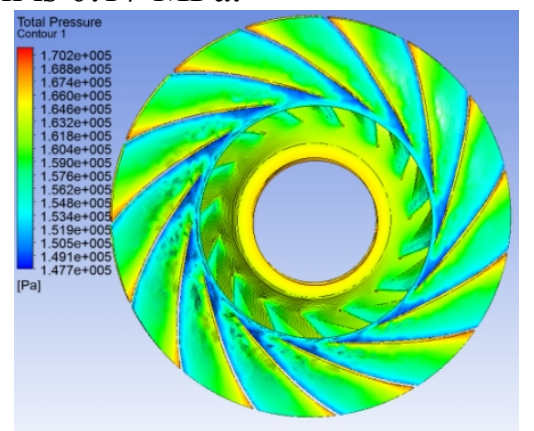

Fig.3 Total pressure of flow field

\section{The transmission medium distribution of impeller flow field}

The distribution of $\mathrm{CH}_{4}$ and $\mathrm{H}_{2} \mathrm{~S}$ in the internal flow field of centrifugal compressor impeller is shown in Fig. 4. $\mathrm{H}_{2} \mathrm{~S}$ is mainly distributed in the suction surface of the impeller blade, and the concentration declines from the impeller inlet to outlet. The maximize concentration is at the blade inlet where near the junction of the leading edge and the wheel cover. $\mathrm{CH}_{4}$ is mainly distributed in the blade pressure surface, the concentration increases from the impeller inlet to outlet, and the largest concentration is at the exit. 


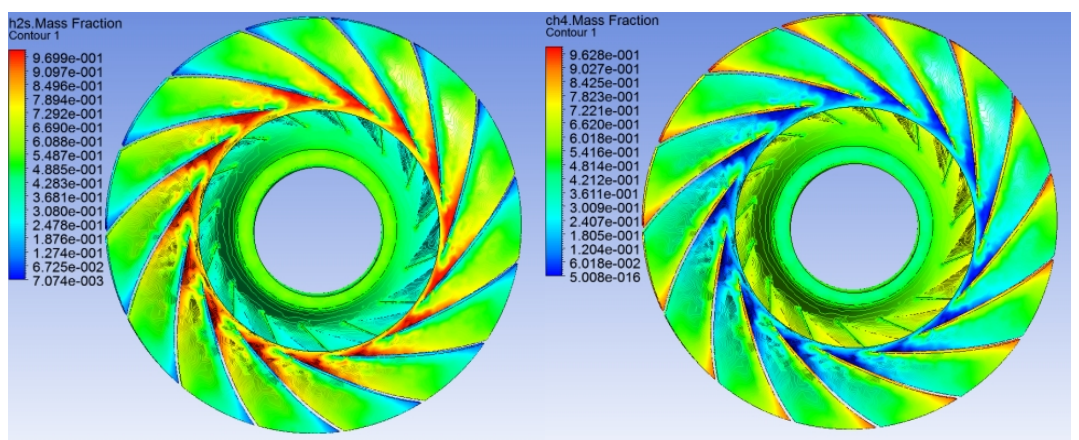

Fig.4 Distribution of $\mathrm{CH}_{4}$ and $\mathrm{H}_{2} \mathrm{~S}$ in the flow field

\section{The fluid-solid coupling analysis of the centrifugal compressor impeller}

\section{Numerical methods}

The centrifugal compressor impeller is made from FV520B steel. The Young's modulus is $210 \mathrm{GPa}$, the Poisson's ratio is 0.3 , the yield strength is $1102 \mathrm{MPa}$ and the density is $7860 \mathrm{Kg} / \mathrm{m}^{3}$.

The centrifugal compressor impeller model is shown in Fig.5. The finite element mesh of impeller model, shown in Fig.6, was built using the unstructured hybrid mesh method and consists of 329807 elements and 489068 nodes.

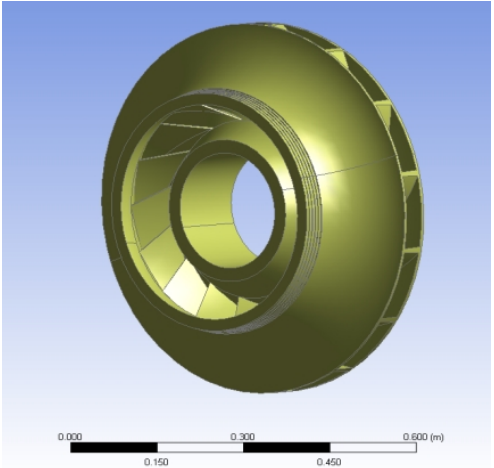

Fig.5 Mechanical model of impeller

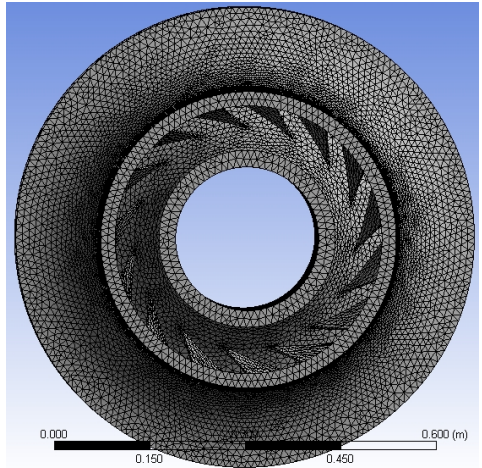

Fig.6 FEA model of the impeller

The centrifugal compressor impeller operates at a high speed, it is subjected to rotary centrifugal force and aerodynamic force. Compared with the centrifugal force and aerodynamic force, the impeller's gravity is negligible due to the high rotating speed. In this paper, the numerical simulation of centrifugal compressor impeller is analyzed in two cases: (1) The load is only centrifugal load which is applied by defining the impeller rotating speed; (2) The load is the combined effect of the centrifugal load and the aerodynamic load which is applied on the impeller blade in the form of static load.

\section{Results and analysis}

The equivalent stress distribution of impeller blade is shown in Fig. 7. In two cases, the tendency of the equivalent stress distribution are the same, both the largest equivalent stress are on the suction surface of blade, near the junction of the leading edge and wheel cover, and the maximum stress are 302.6 MPa and 311.9 MPa. The maximum equivalent stress of the combined effect of the centrifugal load and the aerodynamic load is a little larger than that of centrifugal load.

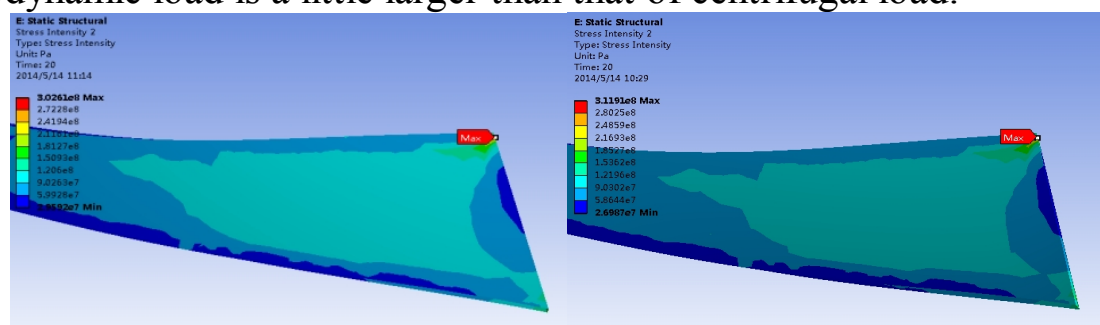

Fig.7 Equivalent stress distribution of blade 


\section{Numerical analysis of the defective centrifugal compressor impeller}

There are usually many pitting corrosion pits on the surface of test sample which could decline the mechanical performance of the sample. The pit can develop into the stress corrosion cracking when it achieves criticality with the interaction of stress corrosion environment and load [4-6]. The pit and micro crack in the blade could caused the change of the pressure field and velocity field. The effect of the change of flow field pressure and the distribution of caustic ion on the crack initiation and propagation is crucial. In order to study the influence factors of stress corrosion crack initiation and propagation, the numerical simulation is done on the impeller with pre-pits which located in the impeller inlet near the junction of leading edge and wheel cover where the equivalent stress and the concentration of $\mathrm{H}_{2} \mathrm{~S}$ are largest. The diameters of the pit are $1 \mathrm{~mm}, 1.5 \mathrm{~mm}$ and $2 \mathrm{~mm}$. The results of numerical simulation are shown in Fig. 8 and Fig.9. The concentration of $\mathrm{H}_{2} \mathrm{~S}$ increases obviously near the pit and the high concentration area reduces with the increase of pit size. The equivalent stress of pit is larger than all others and the maximum stress increase with the increase of pit size.

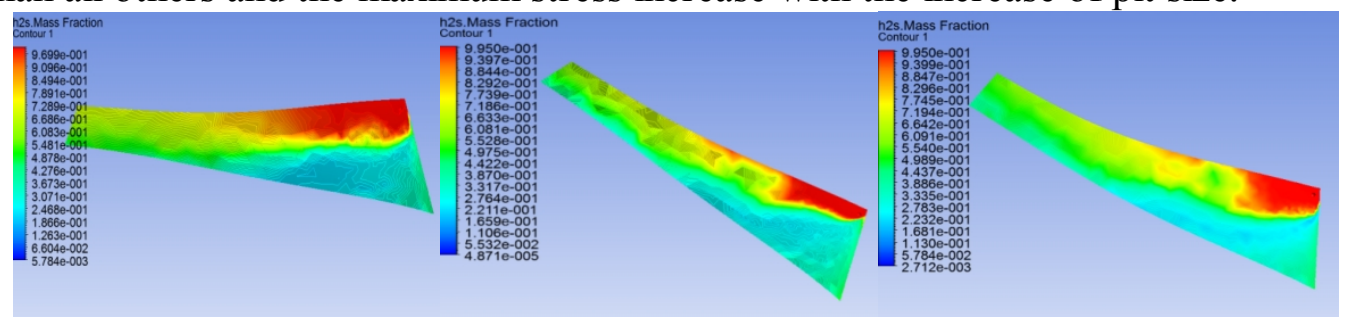
(a) $1 \mathrm{~mm}$
(b) $1.5 \mathrm{~mm}$
(c) $2 \mathrm{~mm}$

Fig. 8 Distribution of $\mathrm{H}_{2} \mathrm{~S}$ around the pit

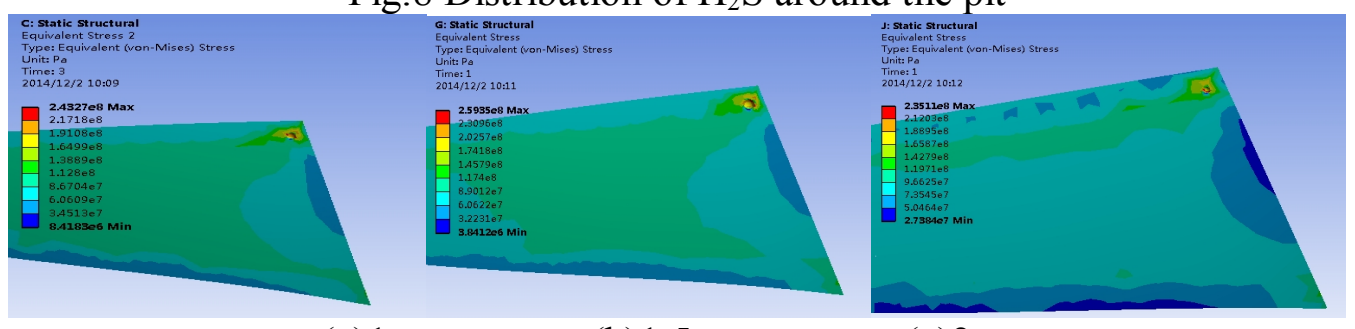

(a) $1 \mathrm{~mm}$

(b) $1.5 \mathrm{~mm}$

(c) $2 \mathrm{~mm}$

Fig.9 Equivalent stress distribution of the blade with pit

\section{Conclusion}

(1) With the effect of aerodynamic load of centrifugal compressor impeller, the pressure of the blade pressure side is significantly higher than that of the suction side. $\mathrm{H}_{2} \mathrm{~S}$ is mainly distributed in the suction surface of the impeller blade, and the maximize concentration is at the blade inlet where near the junction of the leading edge and the wheel cover.

(2) The tendency of the equivalent stress are the same, both the largest equivalent stress are on the suction surface of blade, near the junction of the leading edge and wheel cover,

(3) The maximum equivalent stress of the centrifugal compressor impeller is located in same place with the largest concentration of $\mathrm{H}_{2} \mathrm{~S}$ where the pits happen easily, and develop into stress corrosion cracking.

(4) The concentration of $\mathrm{H}_{2} \mathrm{~S}$ increases obviously near the pit and the high concentration area reduces with the increase of pit size. The equivalent stress of pit is larger than all others and the maximum stress increase with the increase of pit size.

\section{References}

[1] SUI Yongen, TAN Chaoxin. $\mathrm{H}_{2} \mathrm{~S}$ stress corrosion cracking and countermeasure for impeller of centrifugal compressor, J. Compressor Blower \& Fan Technology. 2000(3) 19-22. 
[2] ZUO Jingyi. Stress corrosion cracking, M. Xi’an: Xi’an Jiaotong University Press, 1985.

[3] Greer J B. Factors affecting the sulfide stress cracking performance of high strength steels, J. Materials performance. 14 (3) 11.

[4] MAENG W Y,KANG Y H,NAM T W, et al. Synergistic interaction of fatigue and stress corrosion crack growth behavior in alloy 600 in high temperature and high pressure water, J. J Nucl Mater. 1999(275)194-200.

[5] MARROW T J,BABOUT L,JIVKOV A P,et al. Three dimensional observations and modeling of intergranular stress corrosion cracking in austenifc slainless steel, J. J Nucl Mater,2006 (352)62-74.

[6] HORNER D A,CONNOLLY B J,ZHOU S,et al. Novel images of the evolution of stress corrosion cracks from corrosion pits, J. Corrosion Science: 2011(53)3466-3485. 